\title{
A Discussion on Student Use of Theoretical Frameworks for the Analysis of Discourse and Policy within ECE
}

\author{
Nicola Dunham \\ Massey University \\ Email: N.Dunham@massey.ac.nz
}

\begin{abstract}
The aim of this paper is to explore theoretical frameworks that align with critical pedagogy to inform critical analysis of issues within early childhood education (ECE). This paper is particularly aimed at early childhood student teachers engaging in analysis of discourse and policy associated with ECE in Aotearoa New Zealand, but may hold relevance to other fields and disciplines. The paper begins by defining the concept of critical pedagogy and a theoretical framework, and then proceeds to outline examples of theoretical frameworks relevant to critical pedagogy and ECE. Attention is given to key concepts associated with Freire, Foucault, Bourdieu, and kaupapa Māori. Banking education is the central theme within the framework of Freire; mapping discourse for Foucault, social order and forms of capital for Bourdieu and finally the concepts of ako, poutama and tuakana/teina associated with kaupapa Māori. The paper concludes by highlighting the value of using a theoretical framework informed by critical pedagogy to probe the social landscape for points of inclusion, exclusion and marginalisation. It is concluded that without such a theoretical framework the analysis of educational policy and discourse is likely to verge on a mere stating of current positions, rather than challenging and seeking to reposition issues in support of social justice: a restating as it were.
\end{abstract}

Keywords: Critical pedagogy, theoretical framework, māori, Aotearoa New Zealand

\section{Introduction}

This paper aims to provide a concise overview of a sample of critical pedagogical theories and explain how they can be used to inform policy and discourse analysis. The paper begins by defining the concepts of critical pedagogy and a theoretical framework, and then proceeds to outline examples relevant to critical pedagogy and early childhood education (ECE). In doing so the paper provides responses to the following questions:

1. What is a theoretical framework?

2. How can it help guide critical analysis of discourse and policy in ECE?

3. What theoretical frameworks align with critical pedagogy?

4. What do they have to offer?

5. What limitations do they hold?

The aim of this paper is to present aspects of these theoretical frameworks as a means by which to highlight how discourses within ECE can be analysed. This paper is particularly aimed at early childhood student teachers engaging with critical pedagogy in the analysis of discourse and policy associated with ECE in Aotearoa New Zealand. However, this paper may also be informative to those of alternatives fields and disciplines.

\subsection{Critical Pedagogy}

Critical pedagogy is acknowledged as a complex concept that can be defined in many ways, however, definitions of critical pedagogy have the common aspects of power, position, authority, domination and oppression, to name a few. According to Giroux (Giroux, 2013, p. 29):

Central to any viable notion of what makes pedagogy critical is, in part, the recognition that pedagogy is always a deliberate attempt on the part of educators to influence how and what knowledge and subjectivities are produced within particular sets of social relations. 
This approach to critical pedagogy does not reduce educational practice to the mastery of methodologies. It stresses instead the importance of understanding what actually happens in classrooms and other educational settings by raising questions.

In this instance, critical pedagogy can be seen as a questioning pedagogy, one in which the education is not accepted at face value. Rather, education is seen as a highly contentious and contestable space: a space in which politics, power and justice are in constant state of compromise. At the heart of critical pedagogy is the concept of a justice. For example, according to Kincheloe: "Advocates of critical pedagogy are aware that every minute of every hour that teachers teach, they are faced with complex decisions concerning justice, democracy and competing ethical claims" (2008, p. 1).

\subsection{Theoretical Frameworks Aligning with Critical Pedagogy}

In its most basic sense a theoretical framework provides a way of looking at an issue; directing one's gaze or point of focus. It provides a perspective and structure to examine an issue or phenomenon. For example, "Theoretical frameworks are specific theories about aspects of human existence such as the functioning of politics, the economy, and human relations. These theories can then be applied to the study of actual events" (Trent University, n.d). A theoretical framework introduces and describes the theory that explains why an issue or phenomenon exists. It provides a coherent and structured means to approach the examination of an issue by presenting concepts and variables evident within the existing knowledge base.

Whilst by no means an exhaustive account, the following have been identified as key figures/perspectives developing frameworks aligning with critical pedagogy: Freire, Foucault, Bourdieu and Kaupapa Māori. Each of these theorists/perspectives provides their own unique perspective, concepts and ways in which to explore the world through a critical gaze. Their interest and focus has been shaped and informed by their own personal backgrounds, experiences and research. Each has its own distinctive gaze, or focus, however it is possible to see points of commonality and interrelation between the frameworks.

\section{Critical Consciousness of Freire}

The work of Freire focused on social and political change (McLaren, 1999), and as such education from a Freierian perspective is always regarded as a form of politics. One of the central concepts within a Freierian framework is that of banking education. The concept of banking education was a critique of education systems and the way in which learners are regarded as passive repositories waiting to store the knowledge transferred to them by the teacher. For example, Freire (2000, p. 72) says:

In the banking concept of education, knowledge is a gift bestowed by those who consider themselves knowledgeable upon those whom they consider to know nothing. Projecting an absolute ignorance onto others, a characteristic of the ideology of oppression, negates education and knowledge as processes of inquiry.

Within the concept of banking education, the knowledge determined by the teacher is seen as holding value and relevance.

Freire argued that a model of banking education was dominant within formal education systems and is a means by which citizens are encouraged to be passive and not to challenge the status quo of society. Banking education reinforces perceptions of education as a means by which hegemonic discourses can be maintained as learners are regarded as passive receivers of knowledge, rather than being encouraged to be active knowledge makers who engage in inquiry and critique. For example, Freire stated that:

The more students work at storing the deposits entrusted to them, the less they develop the critical consciousness which would result from their intervention in the world as transformers of that world. The more completely they accept the passive role impressed on them, the more they tend simply to adapt to the world as it is and to the fragmented view of reality deposited in them. (Freire, 2000, p. 72)

Banking education is said to maintain student immersion in "a culture of silence and positions them as objects, outside of history and agency" (Bartlett, 2008, p. 2). Rather than being critical enquirers about the world, the learning process encourages acceptance, denial and would align with what Giroux 
associates with the notion of the organised violence of forgetting; where the past is removed from view and hence from the conscious, where members of society are encouraged to be passive and not to challenge or inquire into why society is the way it is (Giroux, 2014).

Education, Freire argues, should be reconceptualised as an opportunity for agency, autonomy and action. This action relates to the development of critical consciousness (conscientizacao, critical awareness of one's reality. Becoming critically aware, or conscious, draws on the processes of reflection and action; otherwise is known as praxis. The underlying aim of becoming critically conscious is the uncovering of myths about society imbued with hegemonic portrayals of reality and 'truth'. According to Freire, learning is about uncovering "real problems and actual needs" (Freire Institute, n.d). It is further argued that the reality of problems and needs cannot be uncovered without consideration of the "significant historical contexts in which knowledge is produced, engaged, and appropriated" (McLaren, 1999, p. 50).

For Freire, it is through dialogue that critical consciousness is raised, and this he believed was how the true value of education could be realised. Dialogue enables a shifting of position and relation so that there is no longer a dominant one leading submissive others. Instead the teacher and student become one: "The teacher is no longer merely the-one-who-teaches, but is one who is himself taught in dialogue with the students, who in turn while being taught also teach" (Freire, 2000, p. 80). Within the context of Aotearoa New Zealand this notion can be seen within the Māori term Ako in which teaching and learning are regarded as inseparable. This is clearly described within the Māori education strategy $K a$ Hikitia: Accelerating Success 2013-2017 (Ministry of Education, 2008, p. 20): "The concept of ako describes a teaching and learning relationship, where the educator is also learning from the student and where educators' practices are informed by the latest research and are both deliberate and reflective".

Coming to the point of conscientizacao, or critical consciousness, involves engaging in active and analytical dialogue to examine who does and does not have access to education and how this access is permitted or denied (Bartlett, 2008). Freire was most insistent that, "Knowledge emerges only through invention and re-invention, through the restless, impatient, continuing, hopeful inquiry human beings pursue in the world, with the world, and with each other" (Freire, 2000, p. 72). Dialogue and inquiry as processes to raise critical consciousness therefore enable education to become an act of freedom rather than one of domination (Freire, 2000). This freedom enables the creeping oppression evident in society to be made apparent and therefore raising it as an issue for challenging. Instead of becoming accustomed to being oppressed or not seeing that it is happening, education provides a source for freedom giving voice and attention to those who would otherwise be silent and unseen.

Such perspectives can be equated to Giroux's concept of the 'violence of forgetting' in which society is dumbed down in order to maintain the status quo, in the form of existing power relations. Ignorance of oppression is both fostered and supported, in part through the educational process, as stories and experiences of oppression become silenced, dismissed and removed from the landscape of everyday life. Within such a context, discourse and social policy as a means of facilitating access to fair and equal treatment as social citizens, loses momentum and becomes banal and void: action without impact.

\section{Foucault on Mapping a Discourse}

The second theoretical framework to be discussed is based on the work of Foucault. In this section attention will focus on Foucault's notion of mapping a discourse. He equates this mapping process to that of being an archaeologist, who digs through or searches a specific area in order to uncover hidden 'truths' or facets of existence. As identified by Chant (2009, p. 1): A 'truth' is created through a sequence of statements that create a discourse on ideas or knowledge around a particular subject that then becomes widely accepted.

The archaeology of discourse is therefore an act to "uncover the regularity of a discourse practice" (Foucault, 2002, p. 161). By this Foucault means that in order to understand a discourse it is important to uncover for instance, where a discourse has come from, who is talking about something, where and how. Mapping a discourse is also a means of identifying where things are in relation to each other and any connections that might exist between them. Therefore, mapping can be equated to laying it out, or putting it all out in front of you. 
The mapping process involves looking back at where and how a discourse emerged and by looking at wider social influences explores how history shapes concepts. An example used within Foucault's own work is the concept of 'madness'. He uncovered how the concept of madness is socially situated and dependent on the society in which it exists and how concepts and terms change depending on context and what they are measured against.

Foucault was particularly interested in examining why something has become an object of discourse. To this end he points to aspects of diffraction or incompatibility as tensions in understanding how an issue has become an 'issue'. If the instance of Māori is considered Chant identifies: "Truths" about MāChant (2009, p. 2) identifies that "Truths' about Māori, in terms of the Eurocentric discourse on indigenity $(2009$, p. 2) that has evolved in Western democracies with indigenous populations, have constructed a cage within which Māori are perceived as under-developed, uncivilized, and as threats to the established order of society".

Foucault's concept of mapping the discourse provides a means by which such discourse can be teased apart, made apparent with the forces behind such 'truths' becoming exposed. This exposure enables wider social influences to be explored and an examination of how history shapes concepts and how the on-going influence in shaping society through the creation of "regimes of truth". Such truths are in essence power, which pervades society. Truth as power is, according to Foucault, not static but in a state of flux and negotiation, however, renegotiating truth is somewhat challenging when coming from the position of the oppressed as exemplified in the words of Chant $(2009$, p. 2) around discourses of Māori:

Scientific and medical researchers, business and political leaders, medical and health leaders and the media have tacitly constructed Māori to create a negative public perception that adds to the development of this collection of sequential statements. This has resulted in a "regime of truth" through which discourses within New Zealand society can perceive the possibility of Māori as a treatable and untreatable disease.

The defining of Māori comes from a position of power, which is therefore subject to questionable perceptions of truth. Societal conceptions of social issues are therefore a matter of power and not truth (Foucault, 1988). Indeed, a discourse exists in a domain of coexistence with other discourses. The meaning of discursive statements therefore varies according to their use: there is not one single meaning, rather multiple meanings dependent on the influences within the discursive operational field. Therefore, according to Foucault the mapping of a discourse gives form and shape to domains of existence, the influences and contexts in which discourses emerge, exist and co-exist. As stated by Foucault, (2000, pp. 456-457):

A critique does not consist in saying that things aren't good the way they are. It consists in seeing on just what type of assumptions, of familiar notions, of established and unexamined ways of thinking the accepted practices are based... To do criticism is to make harder those acts, which are now too easy.

\section{Bourdieu and Identity as Capital}

Who we are and how we engage with the world is central to understanding reality as social agents. According to Bourdieu, social reality consists of relations between social actors and social structures. In this way the social world is said to present as a symbolic system (Bourdieu, 1989). According to Bourdieu (2007) social roles impact on how social actors behave in social spaces, what they see themselves as being capable of and able to do. Bourdieu's theory proposes that social reality is not made up of objective relations, rather social reality is under continual construction throughout everyday life (Bourdieu \& Wacquant, 1992).

In his approach to the study of the social world, Bourdieu (1989) introduces the concepts of habitus and fields. Habitus is associated with experiences of self, identity, and personal dispositions, with fields relating to the wider social structures, groups, or institutions in which social engagement takes place. According to Bourdieu, it is through the practices and relations between habitus and fields that social ordering or social positions are established and maintained. Habitus is said to refer to the socially created self, or identity, with fields being the spaces of struggle in which social position is continually negotiated (Jones, 2010). 
The position held by a social agent within the social world is said to be dependent on the volume and the weight of the different forms of capital (Bourdieu, 1989). Bourdieu and Wacquant (1992) describe the place of different forms of capital within the analogy of a game in which the tokens or resources of capital held by a player determine the force, position and orientation the player holds within the game, or social structure. They state:

At each moment, it is the state of the relations of force between players that defines the structure of the field. We can picture each player as having in front of her a pile of tokens of different colors, each color corresponding to a given species of capital she holds, so that her relative force in the game, her position in the space of play, and also her strategic orientation toward the game ... the moves that she makes, more or less risky or cautious, subversive or conservative, depend both on the total number of tokens and also on the composition of the piles of tokens she retains, that is, on the volume and structure of her capital. (Bourdieu \& Wacquant, 1992, p. 99)

Within this description of personal resources and one's social position, Bourdieu emphasises the shifting nature of social structures and social positions, which are open to change due to the dynamic relationships between social agents both within and across social structures (Bourdieu, 1994). The value and weight of the resources held by a social actor at any given time are relative to the systems of meaning evident within and across social structures. Bourdieu (1989) identified three forms of capital: cultural capital, social capital and symbolic capital.

\subsection{Cultural Capital}

Cultural capital is said to include things such as "verbal facility, general cultural awareness, aesthetic preferences, information about the school system, and educational credentials" (Swartz, 1997, p. 75). Bourdieu's concept of cultural capital emerged from his research into school achievement and different social origins (Swartz, 1997), and hence a lot of attention is given to educational achievement and gaining credentials. For example, through his exploration of cultural capital Bourdieu departed from understandings of academic success as resulting from natural capacities of for instance intelligence or giftedness. Rather academic success was attributed more to the family environment. Bourdieu's theory of cultural capital is said to consist of three states (Swartz, 1997), which include the:

1. Embodied state: internalised dispositions resulting from socialisation strongly associated with successful participation within the educational system.

2. Objectified state: referring to artefacts such as "books, art works, scientific instruments that require specialized cultural abilities to use" (Swartz, 1997, p. 76).

3. Institutionalised state: referring to a system of educational credentialing especially the mass marketisation of higher education and the power held by such institutions in regards to the reproduction of the unequal distribution of power within society.

Bourdieu emphasised that cultural capital was a major form of social inequality, as some forms of cultural capital are more highly valued than others, and as such can help or hinder social mobility. For example, this is evident in Aotearoa New Zealand through the positioning of Māori medium education (such as Kohanga reo and kura kaupapa) as 'alternative' forms of education outside of the mainstream. This marginalisation of Māori in society can be traced back to the decline of te reo Māori (Māori language), and the repositioning of te reo Māori as a second language, with English as the first language of Aotearoa New Zealand by the mid to late 1900's (Ministry of Education, 2013). Whilst an important vehicle for cultural tourism, Māori ways of being, knowing and doing in the world remain an issue of social inequality (Diamond, 2010).

\subsection{Social Capital}

Social capital refers to the ability of social agents to exist within varied social structures and is regarded as the system of acquaintances and networks, including the collective capital held by members of the domestic unit or family (Bourdieu, 1989). Social capital is thus described as: "the sum of the resources, actual or virtual, that accrue to an individual or a group by virtue of possessing a durable network of more or less institutionalized relationships of mutual acquaintance and recognition" (Bourdieu \& 
Wacquant, 1992, p. 119). Social capital is argued to be significant in education through its association with knowledge. For instance, they argue that:

Social capital [italics as per original] refers to how the quantity and quality of interactions and social relationships among people affects their access to knowledge and information; their sense of expectation, obligation, and trust; and how far they are likely to adhere to the same norms or codes of behaviour. (Hargreaves \& Fullan, 2012, p. 90)

\subsection{Symbolic Capital}

Symbolic capital is the means by which other forms of capital are legitimated. Bourdieu describes symbolic capital as a form of credit or advance: "it is the power granted to those who have obtained sufficient recognition to be in a position to impose recognition" (Bourdieu, 1989, p. 23). Recognition is associated with forms of respect. For example, respect is attached to qualifications as their ownership wields access to social positions that would otherwise be denied. Therefore, qualifications are symbolic capital due to the meaning that is attributed to them through perceptions of power. In this way aspirations of success in society are attached to educational performance. Respect for aspirations that do no align with those of the dominant discourse are therefore not legitimated and as such these aspirations are positioned as alternative, other or less than.

When examining discourse and policy of ECE, Bourdieu's framework enables attention to be given to both the individual, subjective experience of social actors (habitus) as well as the wider social context in which they occur (fields). By attending to both habitus and fields, it is possible to expose the way social groups operate and where points of exclusion and inclusion exist. Bourdieu highlights inequality in society through the system of capital and emphasis that to change society it is necessary to change the way in which society is made. According to Bourdieu, "To change the world, one has to change the ways of world-making, that is, the vision of the world and the practical operations by which groups are produced and reproduced" (Bourdieu, 1989, p. 23). These words highlight that society is open to change. However, in order for change to occur examination must be made of how reality is viewed and practiced: the ways of being and doing, which therefore inform and are in turn informed by ways of knowing in the world. The work of Bourdieu attends to reality as it is experienced at a subjective, individual level, and at the social level of interactions and interrelations.

\section{$5 \quad$ Kaupapa Maori Pedagogy}

Kaupapa Māori is inherently intertwined in Māori language and culture, indeed a part of Māori identity (Mahuika, 2008, p. 2). Rather than drawing on individualised theories, kaupapa Māori is acknowledged as consisting of multiple voices and perspectives: there is no single way of 'being' Māori. As a theoretical framework, kaupapa Māori promotes a Māori world view, or a way of thinking about ideas and practices (Pihama, Smith, Taki, \& Lee, 2004). Using a kaupapa Māori framework means that the points of inclusion, exclusion and marginalisation can be 're-viewed' (viewed again).

At the heart of the discourse of kaupapa Māori is the marginalisation of Māori and the privileging of Pakeha ways of being, knowing and doing. This marginalisation and privileging connects with the core focus of critical pedagogy: namely power, position, authority, domination and oppression. Kaupapa Māori is regarded as posing a challenge to Pakeha hegemonic discourse, and as such acts to reposition power relations. These power relations are argued to lower and devalue the aspirations of Māori (Pihama et al., 2004).

An illustration of the hegemonic discourse of Pakeha and the devaluing of Māori can be seen in the way in which te reo Māori has been positioned as secondary, and arguably an absent language. Te Reo Māori is an essential part of kaupapa Māori as oral tradition was the way in which Māori knowledge was traditionally formed, shaped, constructed and transmitted. However, the history of Aotearoa New Zealand evidences the active attempts to undermine te reo Māori, and as such the Māori culture. These can be seen in the historical outline by the Controller and Auditor General (2012, p. 16):

1903 Nationwide policy to impose a ban on (or discourage) te reo being spoken in the playground. A wide range of punishments used against children who speak te reo at school (including corporal punishment). 


\begin{tabular}{l|l}
\hline 1915 & $\begin{array}{l}\text { Department of Education has an assimilation policy for Māori and low expectations of Māori students. } \\
\text { Annual report includes statement from the Inspector of Native Schools that "So far as the Department is } \\
\text { concerned, there is no encouragement given to [Māori] boys who wish to enter the learned professions. } \\
\text { The aim is to turn, if possible, their attention to the branches of industry for which the Māori seems best } \\
\text { suited." }\end{array}$ \\
\hline $1930 / 31$ & $\begin{array}{l}\text { Attempt by the New Zealand Federation of Teachers to have te reo introduced into the curriculum is } \\
\text { blocked by the Director of Education. In his view, "the natural abandonment of the native tongue } \\
\text { involves no loss to the Māori". Director of Education states that education "should lead the Māori lad to } \\
\text { be a good farmer and the Māori girl to be a good farmer's wife". }\end{array}$ \\
\hline 1950 & $\begin{array}{l}\text { Western influences begin to affect Māori families, who start to raise their children as predominantly } \\
\text { English speakers. }\end{array}$ \\
\hline
\end{tabular}

Within this historical timeline the hegemonic discourse of Pakeha is clearly apparent in the view of the Director of Education in 1930/31, in which claims as to the limited impact of losing their language were 'decided for' Māori. In his view, "the natural abandonment of the native tongue involves no loss to the Māori" (Controller and Auditor General, 2012, p. 16).

Kaupapa Māori acts to realign and reposition Māori within the discourse of society by challenging, questioning and critiquing Pakeha hegemony. Contemporary Kaupapa Maori has been associated with the key elements of the:

1. Validity and legitimacy of Māori

2. Revival and the survival of te reo Māori

3. Autonomy of own cultural well-being and lives

These features relate to Māori "aspirations, philosophies, processes and pedagogies" (Pihama et al., 2004, p. 9). Furthermore, in doing so, "Kaupapa Maori engages with and seeks to intervene in and transform unequal power relations that exist within Aotearoa and which continue to subordinate Maori aspirations [italics as per original] (Pihama et al., 2004, pp. 10-11).

Using kaupapa Māori as a theoretical framework provides a means by which the different ways of seeing and thinking about the world can become an everyday aspect of the educational landscape. Rather than being regarded as 'alternative' to the mainstream norm, education informed by Kaupapa Māori can be repositioned as a legitimated way of being. According to Mahuika (2008, p. 4) Kaupapa Māori provides:

A platform from which Māori are striving to articulate their own reality and experience, their own personal truth as an alternative to the homogenization and silence that is required of them within mainstream New Zealand society. Inherent in this approach is an understanding that Māori have fundamentally different ways of seeing and thinking about the world and simply wish to be able to live in accordance with that specific and unique identity.

As a theoretical framework, some key concepts of significance to the discourse of education include those of ako, poutama and tuakana/teina. Whilst being only a meagre selection of concepts forming kaupapa Māori, these concepts are beneficial to understanding the educational sphere.

\subsection{Ako}

According to Pihama et al (2004, p. 13), ako is central to Kaupapa Māori. Ako is regarded as a term that is openly used by educators seeking to improve disparities between Māori and non-Māori. However, according to Pihama et al (2004) the complexity of the concept of ako can be misinterpreted and hence misrepresented. For instance, "there is not clear separation between ako and other Maori [italics as per original] cultural concepts. Ako was determined by and dependent on Maori epistemologies, values, knowledge and constructions of the world" (Pihama et al., 2004, p. 13). If the concept of ako is removed from the wider context of inter-relation and connection with other cultural concepts, then it potentially loses its meaning. Rose Pere's Te Wheke model, is such an example of the interconnected weave between aspects of Māori life that are important for learning and development (Pere, 1997). 


\subsection{Poutama}

The poutama is a lattice weave depicting steps and is a visual representation of Māori learning and development. The Poutama is complex and holds multiple messages within the one image or concept (Tangaere, 1997). The layered steps of the poutama are likened to the many facets of a person's personality which all come together within a learning experience (Tangaere, 1997). The steps of the poutama relate to new learning experiences, which equate to taking a step up - taking on board something new. The flat areas of the poutama are associated with consolidating learning associated with, for example, acts of practising, repeating, analysing and reviewing amongst others. Once the learning is accomplished the next step can be ascended (Tangaere, 1997). The poutama has been likened to the concept of the zone of proximal development proposed by Vygotsky (1978).

What the poutama brings to Kaupapa Māori pedagogy is an acknowledgment of the importance of taking a holistic approach to learning and education, associated with the concept of kotahitanga. Within the ECE context this holistic self is reflected in an understanding that:

The child's whole context, relationships, with others, and the child's immediate needs at any moment will affect and modify how a particular experience contributes to the child's development. This integrated view of learning sees the child as a person who wants to learn, sees the task as a meaningful whole, and sees the whole as greater than the sum of its individual tasks or experiences. (Ministry of Education, 1996, p. 41)

\subsection{Tuakana/Teina}

According to Tangaere (1997) tuakana/teina derives from the principles of whanaungatanga and ako, which essentially translate as learn and teach. Tuakana/teina is an example of a Māori concept which is connected to the Māori concept of ako, in that the concept of ako means both to teach and to learn, for example: "In the Māori world it is an acceptable practice for the learner to shift roles and become the teacher, and for the teacher to become the learner" (Tangaere, 1997, p. 50). The tuakana/teina model for learning allows for a learning environment in which being knowledgeable is of the norm and in which the care and support for learning becomes a responsibility for all.

The concept of tuakana/teina can be related to that of scaffolding, in which a more knowledgeable or competent other helps one less knowledgeable or competent (Vygotsky, 1978). Typically, in scaffolding theory the knowledgeable other is associated with the teacher, but this could easily be a peer and in so doing would align more closely with Māori pedagogy.

\section{Conclusion}

Throughout this paper attention has been given to outlining a range of theoretical frameworks, which can provide a perspective and structure to examine a social issue or phenomenon. Each of the theoretical frameworks provides a different lens by which discourse can be examined: challenging assumptions and taken for granted knowledge.

As identified in brief, the theoretical framework of Freire and the concept of banking education highlights knowledge as power and how social actors can be relegated to positions of activity of passivity. Foucault's concept of mapping discourse involves looking at where and how a discourse emerged and how issues become issues and the way in which issues change in meaning over time. Bourdieu's contribution reflected social order, and how social structures position people in the world. Finally, kaupapa Māori provides an alternative way to view and think about the world, based on Māori worldviews.

Each of these theoretical frameworks can be of value when applied to analysis of policy and discourse in Aotearoa New Zealand, and in particular to the place of Māori education. These frameworks facilitate examination of, for instance:

1. Who is speaking of Māori education?

2. How is Māori education being talked about?

3. What else is in the social landscape - (Past, present and future).

4. When, how and from where did Māori education become an issue? 
5. How is the place of Māori education positioned and maintained by the existing social structures?

By using the frameworks to respond to such questions can probe the social landscape for points of inclusion, exclusion and marginalisation. As the old adage states 'knowledge is power' and as such these frameworks enable a critical approach to examine whose knowledge it is that holds power, why this is the case, how it is maintained and how it can be changed. Without a theoretical framework the analysis of educational policy and discourse is likely to verge on a mere stating of current positions, rather than challenging and seeking to reposition issues in support of social justice: a restating as it were.

The confines of this paper provide an opportunity to present an overview of what and how theoretical frameworks can be used to guide analysis of social discourse. By providing such an overview it is hoped that such critical analysis and inquiry can be used to raise awareness of assumed and taken for granted knowledge, in the support of social change.

\section{References}

1. L. Bartlett (2008), "Paulo Freire and Peace Education". In Encyclopedia of Peace Education. Information Age Publishing, pp. 39-46.

2. P. Bourdieu (1989), "Social space and symbolic power. Sociological Theory," vol, no. 1, pp. 14-25.

3. P. Bourdieu (1994), "Structures, habitus, power: Basis for a theory of symbolic power". In Culture/power/history: A reader in Contemporary Social Theory. Princeton University Press, pp. 155-199.

4. P. Bourdieu (2007), Outline of a Theory of Practice. Cambridge University Press.

5. P. Bourdieu and L. Wacquant (1992), An Invitation to Reflexive Sociology. Polity Press.

6. L. Chant (2009), "Discourses on Indigenity: The Media, The Warrior Gene and Aggressive Caucasians," Mai Review, vol. 2, pp. 1-4.

7. Controller and Auditor General (2012), Education For Māori: Context For Our Proposed Audit Work Until 2017. Office of the Auditor General.

8. P. Diamond (2010), "Te tāpoi Māori - Māori tourism - Resurgence of the Māori Tourist Industry," Te Ara: The Encyclopedia of New Zealand Available from http://www.teara.govt.nz/en/te-tapoi-maori-maori-tourism/page-4

9. M. Foucault (1988), Madness and Civilization: A History of Insanity In The Age of Reason. Random House.

10.M. Foucault, M (2002), The Archaeology of Knowledge. Routledge.

11.Foucault, M and J. D. Faubion (2000), Power. New Press.

12.Freire Institute. (n.d), "Concepts Used by Paolo Freire," Available from http://www.freire.org/paulofreire/concepts-used-by-paulo-freire.

13.P. Freire (2000), Pedagogy of the oppressed. Continuum.

14.H. Giroux (2013), "Critical Pedagogy in Dark Times". Praxis, vol. 16, no. 2, pp. 27-38.

15.H. Giroux (2014), The Violence of Organized Forgetting: Thinking Beyond America's Disimagination Machine. City Lights Books.

16.A. Hargreaves and M. Fullan (2012), Professional Capital: Transforming Teaching in Every School. Routledge.

17.S. Jones (2010), "Working With Words: A Bourdieuian Approach to Researching Higher Education Entrepreneurship," Methodology: Innovative Approaches to Research, vol, Spring, pp. 8-10.

18.J. L. Kincheloe (2008), Critical Pedagogy Primer. Peter Lang.

19.R. Mahuika (2008), "Kaupapa Māori Theory is Critical and Anti-colonial," Mai Review, vol. 3, Article 4.

20.P. McLaren (1999). "A pedagogy of possibility: Reflecting upon Paulo Freire's politics of education: In memory of Paulo Freire," Educational Researcher, vol. 28, no. 2, pp. 49-56.

21.Ministry of Education (1996), Te Whāriki: He Whāriki Matauranga mo nga Mokopuna o Aotearoa. Learning Media.

22.Ministry of Education (2008), Ka Hikitia: Accelerating Success 2013-2017. Ministry of Education New Zealand.

23. Ministry of Education (2013), Tau mai te reo: The Māori Language in Education Strategy 2013-2017. Ministry of

Education New Zealand.

24.R. Pere (1997), Te Wheke: A Celebration of Infinite Wisdom. Aoako Global Learning New Zealand Ltd.

25.L. Pihama and K. Smith and M. Taki and J. Lee (2004), A Literature Review on Kaupapa Maori and Maori Education Pedagogy. The International Research Institute for Maori and Indigenous Education. 
26.D. Swartz (1997), Culture \& Power: The Sociology of Pierre Bourdieu. The University of Chicago Press.

27.A. Tangaere (1997), "Maori Human Development Learning Theory," In Mai i rangiatea: Maori Wellbeing and Development. Auckland University Press and Bridget Williams Books, pp. 46-59.

28.Trent University (n.d), "Theoretical Frameworks," Available from https://www.trentu.ca/history/workbook/ theoreticalframeworks.php

29.L. Vygotsky (1978), Mind in Society: The Development of Higher Psychological Processes. Harvard University Press. 